\title{
Social security
}

The principles of social security in the Welfare State

Review of how social security developed up to 1979

Description and analysis of the reforms and new attitude to social security under the Conservatives after 1979

Analysis of New Labour's attitude to social security after 1997

\section{BEVERIDGE: FROM THE CRADLE TO THE GRAVE}

The Beveridge Report of 1942 which heralded in the post-war Welfare State proposed a comprehensive National Insurance system which would look after people throughout their lives. Benefits were to be supplied by the state for all those who found themselves in need and who had no apparent means of helping themselves. Contributions, through National Insurance, were to be

National Insurance

A form of taxation levied on those in work and employers. Based on ability to pay, it has a ceiling so that nobody pays above a certain level. It is designed to pay for welfare benefits. paid by all those in work, whether employed or self-employed. In addition, employers were given a duty to make a contribution for all those whom they employed. National Insurance payments were based on income, although there was an upper total limit on contributions.

The Beveridge plan was not a completely novel idea. There was already a form of Welfare State which had come into existence over twenty years before, introduced by Lloyd George. However, the Beveridge plan was far more comprehensive and introduced the idea that membership was to be compulsory.

Once World War II was over, the Beveridge plan could be implemented. The system was indeed comprehensive and offered the following benefits:

Beveridge plan

Named after Lord Beveridge who reported on a future Welfare State in 1942. It proposed a comprehensive state system where all would contribute to services and benefits which would be available to everyone according to need. Benefits would be available to all critical stages of life. 
- maternity grants upon the birth of a child;

- family allowances - a weekly payment to be made for each child in a family;

- unemployment benefit;

- widow's benefit;

- pensions for men over 65 and women over 60;

- death grant for the family of the deceased.

This was indeed a comprehensive system, far more than had been seen before in Britain. As time went by, it was added to by all governments. In principle what happened between 1945 and 1979 was that the system ceased to become merely a safety net and began, instead, to re-distribute real income from the wealthy, who contributed most, to the poor who contributed least but claimed more.

safety net

The concept that the state will be there for those who find themselves in need, providing benefits and services.

Additions and reforms of the system came thick and fast and are too numerous to be detailed here. A general review of the landmarks is therefore offered.

\section{The developing social security system, 1945-79}

- 1945 Family Allowances Act. Benefits were to be paid for each child in a family, other than the first.

- 1946 National Insurance Act. Introduced the basic system. Included pensions for all, sickness benefit for those prevented from working by illness, widow's pension, death grant and unemployment benefit.

- 1956 Family Allowance and National Insurance Act. Provided for a comprehensive system of tax allowances for dependent children up to age 18 .

- 1959 National Insurance Act. Introduced a graduated system of pensions where both the contributions and payments could be made dependent on a person's income.

- 1966 National Insurance Act. Introduced a system of unemployment benefit based on a person's earnings at the time they became unemployed. It also made sickness benefit dependent on a person's normal earnings.

- 1966 Ministry of Social Security Act. Established a new Ministry of Social Security. It also introduced a comprehensive system of supplementary benefits for poor families.

- 1970 Family Income Supplement Act. Gave a larger entitlement to benefit for poor families.

- 1975 Child Benefit Act. Replaced tax allowances for families with children with a child benefit to be paid in cash direct to parents.

This extensive list of developments demonstrates the extent to which social security provision was changed and added to by both Labour and Conservative governments. As one would expect, most of the changes were made by 
Labour, but the Conservatives played their part, with a key development being the introduction of the graduated, earnings-related pension.

Undoubtedly the most significant changes were made by Labour. The introduction of family income supplements, earnings related sickness and unemployment benefit and extensive child benefits were designed to alleviate poverty and re-distribute real income. They were not dramatic measures, but they demonstrated Labour's wish to use the Welfare State as a means of reducing inequality in society.

\section{SOCIAL SECURITY AND THE CONSERVATIVES AFTER 1979}

\section{A new attitude to social security}

When the Conservative party won power in 1979 the social security part of their expenditure commitments came under immediate scrutiny. There were five main reasons why this was so.

1 The new government wished to make inroads into the total level of public expenditure. Firstly, it placed a great burden on taxpayers - and they wished to reduce taxes. Secondly, it was seen as a deterrent to private investment as high government borrowing was thought to 'crowd out' funds which could be used by industry and commerce. The social security bill was the biggest single item in the public finances so it was an inevitable target.

2 Margaret Thatcher had pledged to 'roll back the frontiers of the state' when she took office. It was, therefore, natural that a number of social security commitments should be scrutinised with a view to allowing the state to withdraw its support.

3 Many Conservatives believed that a 'dependency culture' had grown up in Britain. It was suspected that, as people grew to be reliant upon state benefits and learned to expect all kinds of financial support, they would cease to try to fend for themselves. In other words, excessive levels of social security benefit had become a deterrent to enterprise and hard work.

dependency culture

A Conservative belief that if the state provides too many benefits, people will come to depend on them. This will stifle self-reliance, enterprise and hard work. It also keeps people out of the workforce.

4 An important part of the Conservatives' economic policy was the creation of a more flexible labour market. This meant encouraging more people to seek work, if necessary at relatively low wages. High levels of benefit, it was thought, deterred many people from entering the labour market. As things stood in 1979, it was felt that benefits prevented people from taking low paid jobs. 
5 The dependency ratio in Britain was inevitably worsening. This meant that an increasingly large number of people were depending on a shrinking number to contribute to benefits. To some extent this was caused by the ageing population, but it was also caused by high unemployment levels and increasing numbers of poor families. By reducing benefits, the effects of the high dependency ratio would be reduced.

\section{New measures}

During the 1980s there was a steady and prolonged attack on dependency culture. Many of the reforms which Labour governments had introduced were dismantled. The main measures were as follows.

\section{The Social Security Acts 1980}

There were two pieces of legislation in the new government's first full year of office. The rules for supplementary benefits for poor families were tightened up considerably. It also broke the link between a person's earnings and their level of sickness or unemployment benefit. In other words they reverted to a flat rate. Perhaps most startlingly, the first Act broke the link between the level of the old age pension and the average rise in the level of earnings. Instead, pensions would only be guaranteed to rise by the level of inflation. Since inflation rates are invariably lower than the rise in earnings, this was a major erosion in the level of pensions.

\section{Social Security Act 1982}

This required employers to pay a minimum level of sick pay to employees. In effect this eroded the state's responsibility to pay sickness benefit and transferred much of the responsibility to all but the smallest firms.

\section{Social Security Act 1986}

This restricted the payments of housing benefit, an important income supplement for poor families who found it difficult to pay rents, by reducing the numbers entitled and by effectively introducing a ceiling on payments. The Act also reduced unemployment benefits to those under the age of 25 .

\section{Social Security Act 1988}

This took away the young unemployed's entitlement to income support. Instead, they were required to join youth training schemes in order to receive full benefit. This was the beginning of an attack on those young people, who, it was suspected, did not seek work enthusiastically enough. 


\section{Social Security Act 1989}

This built on the previous year's Act. Entitlement was withdrawn from anybody who was unemployed but could be shown was not making themselves available for work. At the same time, anyone who was unemployed for three months was no longer entitled to turn down any job, no matter how poorly paid. This was the principal measure designed to free up labour markets at the lower end of the wage scale.

\section{Statutory Sick Pay Act 1991}

The employer's contributions to sick pay were increased and the contributions made by the state were reduced.

\section{Job Seekers’ Allowance 1993}

This established the principle that unemployment benefit would only be paid to those who were genuinely looking for work and were willing to prove to civil servants that they were actually unemployed. Its effect was to make unemployment benefit more difficult to claim.

The legislation does not tell the full story. Through the 1980s and early 1990s the real value of many benefits was gradually eroded. We have seen that the old age pension was linked to inflation rather than earnings, but other benefits also fell in terms of their real value. Unemployment benefit, sickness and child benefits were all eroded. At the same time some of the benefits which had been paid largely by the state had become the responsibility of employers. For the disabled, too, the welfare regime became tougher. Important tests were introduced to ensure that only those who could prove to medical experts that they were unable to work owing ta a long term disability could claim benefit.

Nevertheless, the story was not all in one direction. Some additions were made to the welfare system. Cold winter payments were introduced for old age pensioners to help with fuel bills, family credits were introduced to allow people to borrow money to buy essential goods and the new income support system for the poor did improve benefits for some families.

\section{ASSESSMENT OF THE CONSERVATIVE REFORMS}

Opponents of these, and many other changes to the system of social security have argued that they fundamentally changed the distribution of wealth and income in Britain. The gap between rich and poor was widened and people spoke once again of 'two nations' being created. For some, the changes were 
seen as little more than an attempt to pay for tax cuts for the middle classes. For the left of the political system it was tantamount to class warfare.

The Labour party, which moved steadily to the left during the first half of the 1980s fought a bitter rearguard action against what they saw as the erosion of the Welfare State. But after their heavy defeat in the general election of 1983, they were powerless to stop the tide. A new pressure group - the Child Poverty Action Group (CPAG) came into existence to bolster opposition to the reforms, but they too fought a losing battle.

One of the objectives of governments of the 1980s and 1990s had been to reduce the Social Security Bill and so stabilise the public finances. This aspect of the policy, however, failed. The Social Security Bill rose during most of the 1980s. High unemployment in the first part of the 1980s and 1990s was the main culprit. The pensions commitment rose inexorably, even though the real value of the old age pension was falling. A higher and higher proportion of the population was falling into poverty and so needed support. Thus opponents argued that, while things might be improving for the majority, they were getting worse for a substantial minority and the state was having to foot the bill.

Supporters of the rolling back of the Welfare State and the toughening of the regime could, on the other hand, point to several improvements. The labour market was indeed made more flexible (aided by the successful attacks on trade union power) and unemployment receded during the 1980s. It was also argued that the dependency culture had been broken, that a new set of values was beginning to affect Britain. The 'work ethic' was strengthening and the performance of the economy, especially the so-called 'enterprise culture' had improved.

There was also a strong body of opinion that welfare benefits had become too easy to obtain. Therefore, by toughening the rules and forcing claimants to justify their dependence, a new kind of social justice had arisen.

\section{NEW LABOUR AND SOCIAL SECURITY}

There is no doubt that a key element in New Labour's philosophy was to attack poverty in the UK, especially child poverty. Gordon Brown, who was always slightly to the left of most of New Labour's leadership, held this belief especially strongly. Indeed one of the first measures introduced after 1997 was the national minimum wage. This device was to have a double effect. Firstly, it would obviously raise the earnings of a substantial number of workers. But secondly it was also expected to affect the social security budget. Fewer families, it was hoped, would have to claim extra support if they could earn a 
decent wage. Since its introduction, furthermore, the level of the minimum wage has risen faster than inflation - in other words its real value has increased. Having done this, Brown and the cabinet turned to the social security system.

\section{Welfare to work}

This idea was to change public and governmental attitudes to the use of welfare - social security, in particular, completely. The previous Conservative administrations had tried to reduce many benefits on the assumption that this would force more people into the workforce and so make them less dependent on the state. The New Labour plan was to use new welfare policies as an incentive instead of low levels of benefit as a sanction. There would still be a harder regime for those who refused to take up the system of incentives (perhaps even harder than the Conservatives had envisaged).

The change in policy direction came to be known as 'welfare to work' suggesting that the welfare system would help people back into the workforce rather than force them. It was, in other words, to be a carrot rather than a stick

\section{The poverty trap}

One of the main problems causing both poverty and unemployment in the UK has been the so-called poverty trap. This phenomenon occurs under a particular set of circumstances. Where nobody in a family is working and they rely on state benefits to live, there may be no incentive for anyone to find employment. If somebody did and began to earn money, the value of the earnings would be instantly eroded by taxation. At the same time the family would begin to lose many benefits which are means-tested. With some income coming in, such benefits as housing benefit, school uniform and meals allowances, income support and the like would be lost. The net effect of all this was often that a family was actually worse off by working than by not

\section{poverty trap}

A situation where families find there is no incentive to find work. The double effect of paying tax and losing benefits when they start work may result in a reduction in net earnings. working. They were, therefore, in a poverty trap. It was a disincentive to work and, for those who nevertheless chose to find employment, it actually increased poverty.

There are essentially three ways to attack the poverty trap:

1 Raise earnings at the lower end of the wage scale. This was partly achieved by introducing the minimum wage.

2 Reduce or eliminate taxation at low earnings levels. To achieve this Brown introduced a new 10 per cent tax band to replace levels of 20 per cent or 22 
per cent for low earners.

3 The most difficult measure concerns social security benefits. It was here that the most radical proposals were made by the new Labour government. Though many benefits would continue to be means tested, and therefore lost when a family raised its earnings, a system of tax credits could be used. Effectively this meant compensating such families for the loss of benefits and ensuring instead that their effective income level would be increased. This was designed, in the end, to ensure that anyone would gain by seeking and finding employment. It is discussed in more detail below.

\section{The attack on poverty: selective universality}

tax credits

A system where the tax authorities actually pay back taxes to poor families. This improves their financial status and can reduce poverty.

This apparently odd phrase (selective universality) has been used to describe the overall social security policies of the post-1997 Labour governments. It suggests a system which is designed to be of general benefit, but which targets action upon poor families, and especially those with children.

The main measures which are designed to achieve this targeting are as follows:

- The working family tax credit is a system of subsidising families where one or more of their members is earning. It compensates for

selective universality

A name applied to New Labour's Social Security policies after 1997. It refers to the idea that, although all benefits have been reformed, there is a focus on those groups who are especially in need through no fault of their own. the loss of benefits as earnings rise. It is designed to achieve an effective minimum level of income for such families. By 2002 this reached $£ 214$ per week. The family will actually receive money from the inland revenue, rather than simply paying to them.

- A child tax credit is also becoming available, again to ensure that working families are rewarded with extra income, rather than punished by the tax system.

- A new stakeholder pension scheme was introduced, specially for those unable to take part in private pension schemes. These are discussed below. A number of other measures to help pensioners are also described in the next section.

- Help became available to subsidise the cost of child care for working parents. Again this is described below.

- Higher levels of income support in general became available for families with children.

We can therefore see that benefits have tended to be aimed mainly at poor 
families, pensioners and those who have dependent children - traditionally the groups in society who are the poorest. We can now look at some of the measures in a little more detail.

\section{Pensions}

Gordon Brown decided at the outset to retain the link between the state pension and the rate of inflation. He resisted calls from his own party and pressure groups such as Age Concern and Help the Aged to restore the link between pensions and average earnings. This led to perhaps his greatest political error. In 2000, when inflation was at a particularly low level, the index-linked pension rise came to only 75p per week. It had been correctly calculated and Brown claimed that it was fair. But the psychological effect of such a tiny increase was devastating. At one point, indeed, it seemed to threaten the government's re-election prospects.

What had been lost in the political controversy which raged around the increase was the fact that Brown was attempting to target benefits on poor pensioners only. The state old age pension was not means tested and paid on an equal basis to all - from dukes to dustmen - as had been said. By raising means tested minimum income support for pensioners, he claimed to be helping those who needed the support, rather than everybody. So, even if the real value of the pension was falling, poor pensioners would be protected. By 2003 it is intended to raise the minimum income for a single pensioner to $£ 100$ per week, and $£ 154$ for a married couple. In addition benefits are available for those with disabilities and chronic illnesses.

But the Brown plan - another example of selective universality - did not convince the doubters. So in 2001 he was forced to give above-inflation pension increases. He also substantially increased the cold weather bonus (now available whatever the weather), the pensioners' Christmas bonus and a free TV licence for those over 75 . These measures were successful in heading off opposition and the pensions issues did not affect the general election result.

Labour's other plan for the elderly has been the introduction of the stakeholder pension. For those who do not enjoy occupational pension schemes or cannot afford to have their private pensions, the state is now providing its own system. This is designed to 'top up' the state pension, which, as we have seen, is likely to continue to fall back below typical living standards. All large employers must organise a stakeholder pension

stakeholder pensions

A new system of old age pensions. People may start their own pension plan and will enjoy tax relief on

contributions. Every large employer must offer such a scheme to their employees, though they do not have to contribute. It is needed because the value of the state pension is being eroded and the state cannot afford to meet the increasing demands of an ageing population. 
scheme for their workers, though they do not have to contribute. The contributions to the stakeholder pension are tax free, though there is a ceiling as to how much can be put into the scheme.

Stakeholder pensions are not designed to replace private schemes - indeed the government encourages them. However, there is a recognition that the state cannot sustain the growing expenditure on the old age pension. Individuals will be forced to make their own additional contributions.

\section{Child poverty}

As we have seen, Gordon Brown's main priority has been child poverty. A significant number of measures have been introduced to try to alleviate the problem:

- The real value of child benefit has been increased substantially after over a decade of erosion.

- The state offers up to 70 per cent of the cost of child care to any poor parent who wishes to work.

- Child tax credits are available for poor families.

- Working families with children are now offered substantial income support

- The working families tax credit system, as shown above, is designed to have a major impact on children's welfare.

- Perhaps less directly, but nevertheless creating an impact on poorer families with children, especially lone parents, a place for all 4-year olds is not guaranteed at nursery school. In 2002 it was announced that the government also intended for places for every 3-year old to be available for all parents who needed it. The existence of such places for children is designed to help more parents with child-care responsibilities to seek employment.

Despite the measures and Brown's claim that he has taken hundreds of thousands of children out of poverty, his aim to eradicate the problem altogether is still very far off. Low wages and areas of high unemployment stubbornly refuse to go away and these may have to be the subject of future policies.

social exclusion

Part of New Labour philosophy. It refers to those who are deprived and have a variety of social problems with a variety of causes. Reforms to the social security system are a part of an overall strategy of reducing social exclusion.

\section{Social exclusion}

The term social exclusion, a key element of New Labour's philosophy, refers to those groups in society who have been seriously disadvantaged by a variety of circumstances. Some of Labour's Social Security policies have been directed at this problem. Four particular aspects of social exclusion can be used as examples of how welfare policy has been used to try to attack it. 
1 Youth unemployment has been perhaps the most severe problem. It has given rise to high crime rates, drug use and poverty. To attack it, a new deal was introduced for the young unemployed. It basically gave young people four choices at age 16 . They could stay on in education, in which case, if they were from a poor family, benefits would be maintained as an incentive. They could go onto recognised training schemes in which case, again, they would receive benefits. Thirdly, they could seek employment and would receive an allowance while doing so provided they attended training for job seeking and attended designated interviews. Finally they could do none of the above, in which case benefits would be withdrawn.

2 Lone parents created problems, both in terms of long-term dependency and the quality of care given to children. They were offered a new deal, like the young unemployed. Those who chose to look after their children would be rewarded with increased benefit. If they opted to seek work, the state would pay for up to 70 per cent of child-care costs so there would be no 'poverty trap' for them.

3 Child poverty is a further form of social exclusion. Not only is it seen as an evil per se, it also leads to other problems such as low educational attainment, truancy, crime and drug abuse. By eliminating child poverty it is assumed that many of these problems will dissolve.

4 General unemployment has been tackled by attempts to reduce the poverty trap as shown above. It is a cause of family poverty, of child poverty and of many other social problems. Clearly, the enduring health of the economy has helped ease unemployment since 1995, but the effects of 'welfare to work' policies may also have been a benefit.

\section{NEW LABOUR: AN ASSESSMENT}

In Labour's first term, and after their election victory in 2001, attention has tended to centre upon policies towards public services such as health, transport, education and crime. The failure of the party in these areas has put their future electoral prospects in doubt. This has tended to overshadow the progress they have made in the field of social security. There is no doubt that they have made some progress in reducing inequality and in dealing with poverty. The claims are grand ones and the party has very far to go. It may well be that Gordon Brown has overstated the achievements.

However, there remains some concern that the Labour government's refusal to use the tax system to re-distribute income from rich to poor will mean that progress will be limited. The role of welfare in bringing more people into the workforce and in reducing poverty can only go so far unless Brown is prepared to raise taxes at the top end. There is no immediate prospect of this happening. 
Making fundamental social changes is a long-term project. The effects of ending child poverty and social exclusion will only be seen after a new generation has grown up. It is too short a time period to make a final judgement on New labour's performance.

\section{AN OVERVIEW OF WELFARE AND SOCIAL SECURITY}

We can usefully divide the post-war period into the folowing four main phases where welfare.

1 1940s to 1960s. In this period social security was largely seen as a safety net protecting those who were deprived through no fault of their own. It was also there to provide support for people at times when need is greatest - when children are young, when a person is unemployed, when there is sickness and when people are old.

2 1960s to 1970s. When Labour was in power in this period they attempted to use the Welfare State, in combination with direct taxation, as a means of redistributing income and reducing inequality.

3 1980s to early 1990s. This saw the Conservative attack on the dependency culture and their attempt to create a more flexible labour market. Welfare benefits were reduced, partly to prevent too many people relying on the state and partly to prevent cash benefits being used to keep people out of the workforce.

41997 to the present. This period has seen New Labour's programme of welfare to work and its attack on poverty. Social security was to be used as an incentive for enterprise and for people to seek work, rather than as a safety net or a means by which people could continue to be dependent on the state.

\section{SAMPLE QUESTIONS}

1 To what extent have the principles of the Welfare State been eroded by social security changes since 1946 ?

2 How did the Conservatives seek to end the dependency culture after 1979 ?

3 How has New Labour attempted to attack poverty after 1997 ?

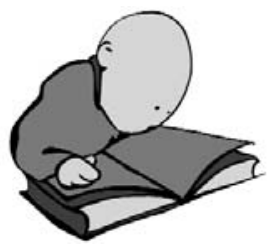

4 In what ways has the Labour government after 1997 sought to reduce child poverty? 